\title{
A Transit Technology Selection Model
}

Jeffrey M. Casello, Geoffrey McD. Lewis, Kevin Yeung, Deborah Santiago-Rodríguez

University of Waterloo

\begin{abstract}
This paper presents an easy-to-use model to assist in technology selection for transit planning. The model computes annual costs for two technologies-currently BRT and LRT-for a system with characteristics specified by the user and from "real-world" operating data. The model computes the annualized capital and operating costs over a wide range of demand; it also calculates location-specific, energy-related emissions for both technologies' operations. Most importantly, the model allows the user to test the sensitivity of the technology selection result to nearly all inputs. The model is applied to a recent case in Waterloo, Ontario, Canada, to verify its functionality. The results show that, economically, these two technologies result in very similar annual costs for "normal" demand levels. As a result, small changes in assumed input values for period of evaluation, interest rates, labor costs, and infrastructure costs can result in a change in recommended technology.
\end{abstract}

\section{Introduction}

Many North American cities are planning to upgrade or implement new public transportation infrastructure with the goals of increasing transit ridership and positively influencing land uses. Typically, the planning process begins by identifying multiple candidate alignments and technologies from which a tractable number of viable alternatives is generated. For these options, a more detailed assessment is conducted to estimate benefits-typically measured as congestion reduction, mobility enhancements, environmental impacts, or land use change-and costs-typically estimated as a net present value of investment and long-term operating costs. Ideally, the option with the "best" combination of benefits and costs is selected, although local political or other inputs often influence the decision-making.

Naturally, the success of this process depends heavily on the quality of the forecasts from which many of the benefits and costs are calculated. The projected ridership is particularly important in that incorrect estimates can produce significant errors in future operating and (to a lesser extent) initial infrastructure costs. Similarly, assumptions about energy and labor costs can strongly influence the ultimate choice of alignment and technology.

To address these challenges, we approach the transit technology selection process with a slightly different perspective. Instead of asking what is the "optimal technology" for an 
assumed demand level, we develop an easy-to-use model that computes life cycle costs for candidate systems - currently bus rapid transit (BRT) and light rail transit (LRT) - over a range of demand levels. The model also uses spatially-specific information on energy sources to generate estimates of commonly-produced airborne pollutants over the analysis period. Most importantly, the model allows for the testing of sensitivity of technology selection to most capital and operating cost assumptions. The overall results from the model allow the user to make better-informed decisions on the suitability of a technology recognizing the uncertainty of future forecasts. In our current formulation, we assume that demand does not vary as a function of technology (i.e., bus systems and rail systems attract the same ridership) and fares are equal. These two assumptions result in equal revenues for the two technologies, allowing us to concentrate on a comparison of cost estimates.

The remainder of the paper is organized as follows. The next section reviews the literature on similar modeling efforts, followed by a description of the components of the model. A case study from the Region of Waterloo, Ontario, is presented to demonstrate the model's functionality. In Section 5, the results obtained from the model's application to the case example are discussed. Next, we use the model results to comment on technology selection in the developing world, where high capacity bus systems are the norm, and, finally, the conclusions section summarizes the work and describes possible future research.

\section{Previous Literature}

Around the world, there have been numerous debates on the preferred transit technology-bus or light rail-for medium-capacity transit corridors. Amongst these debates, Hensher and Waters (1994) have stressed the importance of moving the discussion and rhetoric beyond one that is based on opinion and beliefs towards one that measures the merits and costs of each technology. Edwards and Mackett (1996) echoed this argument by suggesting that the decision-making process for transit systems require further rational structure.

One example of the ongoing debate between LRT and BRT is in the San Fernando Valley of Los Angeles. In 2014, the California state government reversed a 1991 law that banned surface rail traversing through this area of Los Angeles (Nelson 2014). Local businesses and organizations have reacted positively to this decision and are advocating for the conversion of the existing Metro Orange BRT line to light rail (Nelson 2014). One other project that is currently considering either LRT or BRT technology discussion is the East San Fernando Valley Transit Corridor in Los Angeles (Metro 2014). Even though LRT can now be considered in San Fernando, arguments regarding the cost-effectiveness of BRT located along freeways and high occupancy or toll lanes posed by Gordon (1999) may still resonate with decision-makers, as there are limited funds to implement new transit infrastructure. This example demonstrates the continuing need for a methodical evaluation of transit capital and operating costs.

The methodical evaluation of technologies for transit corridors based on cost has been the subject of extensive research. Meyer et al. (1966) conducted a cost comparison of auto, bus, and rail technologies along a hypothetical transportation corridor. This seminal work calculated the average cost to transport a passenger on each mode based on aver- 
age values of parameters, including infrastructure, vehicle, labor, and maintenance costs, as well as ranges of variables such as system length and travel demand. The work by Meyer et al. has been fundamental to the economic analysis of transportation projects.

Numerous studies have since explored specific input parameters of cost models to better understand their influences on the cost of bus and rail transit systems. Allport (1981) suggested the ideal passenger demand ranges where bus, light rail and metro are the most cost-effective and identified that personnel wages account for a majority of all costs. Vuchic (2005) also found that the selection of bus and rail systems depends on passenger demand and labor costs. Taylor et al. (2000) developed a model that captured the variation in operating cost to provide different levels of transit service during the day in Los Angeles. Bruun (2005) compared the range of operating costs for light rail and bus rapid transit in the Dallas area. He noted that the marginal cost of providing additional light rail service is less in both the peak and non-peak periods. Tirachini et al. (2010) determined the operating speed threshold at which rail and bus are equally cost-effective. Hess et al. (2005) noted in a review of BRT implementation costs in American cities that the range of capital costs for BRT systems varies and is dependent on the planned level of service for the system.

Many other researchers also have documented the ranges of input capital and operating parameters for LRT and BRT systems. Table 1 is a summary of these studies.

TABLE 1. North American Values Derived from the Literature

\begin{tabular}{|c|c|c|c|}
\hline Input & LRT & BRT & Sources \\
\hline Operational speed $(\mathrm{km} / \mathrm{hr})$ & $20-70$ & $20-50$ & $\begin{array}{l}\text { - LRT: SEWRPC (1998), Hammonds (2002), City of Calgary (2011), Vuchic (2005) } \\
\text { - BRT: APTA (2010), CUTA (2007) }\end{array}$ \\
\hline Vehicle capacity (sps/veh) & $180-245$ & 120 & $\begin{array}{l}\text { - LRT: City of Calgary (2011), Siemens (2007), Vuchic (2005), Casello et al. (2009) } \\
\text { - BRT: Zimmerman et al. (2004) }\end{array}$ \\
\hline Labor cost $(\$ / \mathrm{hr})$ & \multicolumn{2}{|c|}{$20-30$} & - Vuchic (2005); CUTA (2011) \\
\hline Energy consumption & $\begin{array}{l}3.5-3.7 \\
\mathrm{kWh} / \mathrm{km}\end{array}$ & $\begin{array}{l}0.91-1.72 \mathrm{~L} / \\
\mathrm{km}\end{array}$ & $\begin{array}{l}\text { - LRT: City of Calgary (2011) } \\
\text { - BRT: Hemily et al. (2003) }\end{array}$ \\
\hline Energy cost & $\begin{array}{c}\$ 0.075- \\
0.16 / \mathrm{kWh}\end{array}$ & $\begin{array}{c}\$ 0.72-1.08 \\
/ L\end{array}$ & $\begin{array}{l}\text { - LRT: EIA (2012) Manitoba Hydro (2012) } \\
\text { - BRT: World Bank (2010) }\end{array}$ \\
\hline Vehicle capital cost (\$M/veh) & $3-6$ & $0.5-1$ & $\begin{array}{l}\text { - LRT: Casello et al. (2009) } \\
\text { - BRT: Casello et al. (2009), Levinson et al. (2003), Danaher (2009) }\end{array}$ \\
\hline Service life (yrs) & $20-40$ & $8-15$ & $\begin{array}{l}\text { - LRT: Transportation Action Ontario (2012) } \\
\text { - BRT: Levinson et al. (2003) }\end{array}$ \\
\hline Vehicle maintenance $(\$ / \mathrm{km})$ & $0.40-0.60$ & $0.1-0.5$ & $\begin{array}{l}\text { - LRT: Pilgrim (2000) } \\
\text { - BRT: Hemily et al. (2003) }\end{array}$ \\
\hline $\begin{array}{l}\text { Station construction cost } \\
(\$ M)\end{array}$ & \multicolumn{2}{|c|}{$0.5-9.0$} & $\begin{array}{l}\text { - Danaher (2009), Hsu (2005); Kittleson and } \\
\text { - Associates (2007) }\end{array}$ \\
\hline $\begin{array}{l}\text { Infrastructure construction } \\
\operatorname{cost}(\$ M / k m)\end{array}$ & $25-113.5$ & $6.5-105$ & $\begin{array}{l}\text { - LRT: Casello et al. (2009) } \\
\text { - BRT: Casello et al. (2009), Levinson et al. (2003) Danaher (2009), Kittleson and } \\
\text { Associates (2007) }\end{array}$ \\
\hline
\end{tabular}

Currency converted to US\$2011 
This sample of studies suggests that the cost of each transit technology is sensitive to the input cost parameters, and an analysis of the sensitivity of these parameters on the overall cost is warranted. The need to do sensitivity analysis has been recognized in Keeler and Small (1975), who specifically analyzed the cost for transit at a low (6\%) and high (12\%) interest rate. Other sensitivity analyses have been conducted for particular parameters in the studies mentioned previously in this review. However, there remains a need in transit planning for a comprehensive user interface that allows planners to input and test parameters that are manageable by the transit agency to compare the overall cost of various technologies, most often LRT and BRT. The cost models by Qin et al. (1996) and Hsu (2005) have a user interface to allow transit planners to input parameter specific to their local context. Yet, these two interfaces lack the ability to test the sensitivity for the parameters included in the cost model. Our research attempts to fill this gap within the literature.

The economic analysis of transportation modes provides a good basis for comparison between light rail and bus rapid transit, but it should not be the only factor in decision-making. Vuchic (1999) argues that transportation systems are much more complex than what is represented in a pure economic evaluation that ignores other objectives in transportation planning. One such objective could be the minimization of environmental impact through vehicle emissions. Puchalsky (2005) conducted a very rigorous comparison of the emissions generated by buses and rail vehicles. He concluded that at equal levels of service, LRT produces lower greenhouse gas (GHG) emissions than BRT systems. Another study by Chester et al. (2010) compared the life-cycle energy consumption and emissions for urban transportation systems in New York, Chicago, and San Francisco and concluded that Chicago, which relied more on electric vehicles, experienced lower energy consumption and GHG emissions. The authors noted the potential benefit of further reductions when trips are shifted onto higher-capacity transit vehicles. These two recent studies demonstrate the importance of including emissions data in the decision-making tools for LRT and BRT projects. While there has been effort by researchers to quantify and compare the indirect costs of transit emissions in cost models (Keeler and Small 1975; Parajuli and Wirasinghe 2001; Wang 2011; Griswold et al. 2013), our model is distinct in that does not attempt to convert the emissions into an annual cost, as this quantification includes additional assumptions for parameters. Rather, we present the annual emissions and allow the decision-maker to determine how influential environmental impact is on the overall transit technology selection.

\section{Model Development}

The goals of this research are to fill some of the gaps identified in the literature and create a foundation for transit mode evaluation from which we and other researchers can advance the state of knowledge and the practice. To these ends, we develop an easy-touse model that quantifies life cycle costs as a function of demand, allows the user to test the sensitivity of life cycle cost to input assumptions, and estimates the environmental impacts of system operation. The model formulation consists of five components: the representation of demand, investment cost calculations, operating cost calculations, sensitivity analysis, and emissions computations. 


\section{Representing Demand}

Transit demand can be quantified in many ways: peak hour (period) boardings; off-peak boardings; (week) daily boardings; or annual boardings. In our case, we are interested in representing demand to facilitate the calculation of operating cost and fleet requirements. To this end, the model requires the value of the highest passenger demand, $P_{\max }$, in passengers per hour, for the most heavily-used section-the Maximum Load Section (MLS) - along the proposed line. Naturally, $P_{\max }$ varies as a function of the time of day and day of the week. To account for these variations, we define three weekday and two weekend analysis periods. On weekends, we consider a daytime (higher) demand and a night-time (lower) demand. On weekdays, we consider:

1. Peak period, representing the highest passenger demand, typically in the morning and evening rush hours

2. Off-peak period, representing moderate travel demand outside of the peak periods

3. Weekday evening periods, representing low travel demand

In all cases, we allow the user to define the duration of these periods. If the demand profile remains constant throughout the day, the analyst can define one period and indicate that this demand scenario lasts for all operating hours. Alternatively, for systems with highly-variable demand, the model allows the analyst to define multiple periods with different demand and different levels of service provided. For simplicity, we allow the analyst to input non-peak demand levels as a function of peak demand levels (e.g., $0.4 \times P_{\max }$ ).

\section{Calculating Investment Costs}

Transit system investment costs considered by the model can be grouped into three categories: alignment costs, station costs, and vehicle acquisition. Typically, the costs to construct the physical alignment, including right-of-way acquisition, civil works, utilities, electrification, riding surface, etc., are estimated in terms of $\$$ per kilometer. In the model, the analyst inputs both the infrastructure capital cost per km (ICC) and the system length (L) from which the model calculates the total infrastructure capital cost (TICC).

Capital costs for stations can vary significantly based on the quantity and sophistication of the infrastructure required. At the planning level, the total costs of stations are estimated by the product of the number of stations and the expected (or average) cost per station. Both the number of stations (NSta) and the average cost per station (SCC) are input by the analyst, from which the total station cost (TSCC) is calculated.

The other major infrastructure component the model considers is vehicle acquisition. The number of vehicles necessary is calculated endogenously in the model, as outlined by Casello and Vuchic (2009, p. 743). Conceptually, the approach is as follows:

1. For the largest passenger demand, $P_{\max }$, the model calculates the necessary frequency of service ( $f$ vehicles per hour) to provide sufficient capacity. This varies as a function of vehicle capacity ( $c_{v}$ persons per vehicle) and vehicle load standards ( $\propto$ persons per space), both of which are user inputs. In the LRT case, the user can opt to operate coupled vehicles which, in effect, doubles the capacity and reduces the frequency of service by half. 
2. The model translates the frequency of service into an operational headway ( $h$ minutes), usually calculated so that $60 / h$ is an integer. This restriction is relaxed for very short headways-less than 2 minutes.

3. The model calculates the time necessary for one vehicle to complete a full cycle-one round trip including terminal times. This cycle time ( $T$ hours) varies by system length $(L \mathrm{~km})$, operating speed ( $v_{o} \mathrm{~km}$ per hour), and duration of terminal times ( $t_{t}$ minutes).

4. The model computes the total number of vehicles necessary $(N)$ by dividing the cycle time converted to minutes (60T) by the operational headway ( $h$ minutes) in peak operation and rounding up.

5. The model then calculates fleet size by multiplying $N$ by a spare ratio (spare percent), the number of vehicles needed in reserve in case of breakdowns, also a user input.

The initial vehicle acquisition costs, IVC (\$), can then be written as:

$$
I V C=N \times(1+\text { spare }) \times V C C
$$

where VCC is cost per vehicle (\$).

It is typical for the analysis period to exceed the service life of transit vehicles. As such, additional vehicles may need to be acquired during the analysis period. The model allows the user to specify a service life for vehicles; the model then calculates the future costs to replace vehicles at the end of their service lives. For simplicity, it is assumed that all vehicles in the fleet are replaced in the same year.

The final step in the investment cost analysis is to convert all investments to annualized costs. This is done using standard time value of money equations with a user-specified interest rate and period of analysis.

\section{Calculating Operating Costs}

The model considers three components to operating costs: labor, energy, and maintenance. Labor costs are calculated as a function of vehicle operating hours; energy and maintenance costs are a function of vehicle kilometers traveled.

Vehicle operating hours are estimated endogenously in the model on an annual basis as a function of the daily demand profiles and the cycle time. Suppose on weekdays, a hypothetical system operates for 18 hours per day, with 4 peak hours and 14 off-peak hours. Further suppose that the number of vehicles in service (computed from $P_{\max }, \mathrm{c}_{v}$ and $\propto$ ) in the peak period is 10 , whereas in the off-peak, six vehicles are necessary. In this case, the total vehicle hours for the day are given by:

4 peak hours $\times 10$ vehicles +14 off-peak hours $\times 6$ vehicles $=124$ veh $\times$ hrs

The model computes these daily vehicle hours for all time periods, on both weekdays and weekends. Standard numbers of weekdays and weekend days are used to convert the daily hours to annual hours. The final step is to compute the labor costs as the product of labor hours and a user-provided labor rate $(\$ / h r)$. 
To calculate energy costs, a similar approach is taken. The total daily service provided is calculated as a function of demand and system length; the output is veh-km for each operating day. Energy consumption is calculated as the product of distance traveled and a user-specified energy use factor. For diesel systems, the daily fuel requirement (liters/ day) is the product of veh-km/day and liters/veh- $\mathrm{km}$. For electric-powered systems, the daily electricity requirement is calculated in $\mathrm{kWh}$ as the product of veh-km/day and $\mathrm{kWh} /$ veh-km. In both cases, the daily consumption is converted to annual consumption. The total annual cost is the product of annual consumption and energy (liters or kWh) costs.

Maintenance costs are broken down into two components: vehicle and alignment. Vehicle maintenance costs are calculated as the product of annual veh- $\mathrm{km}$ traveled and the maintenance rate $(\$ / v e h-k m)$. The alignment cost is computed as the product of the system length, $\mathrm{L}$, and the maintenance rate $(\$ / \mathrm{km})$. All of the operating costs are estimated as annual costs.

\section{Calculating Emissions}

The model calculates the annual quantities of the most commonly considered transportation emissions: $\mathrm{NO}_{x}, \mathrm{SO}_{x}$, and $\mathrm{CO}_{2}$ equivalents (including $\mathrm{CO}_{2}, \mathrm{~N}_{2} \mathrm{O}$, and $\mathrm{CH}_{4}$ and accounting for differences in global warming potential). The method by which emissions are quantified depends on the fuel source. For diesel-powered systems, the model assumes "typical" emission generation in grams per liter; total annual emissions are calculated as the product of the emissions per liter and the total liters of fuel consumed.

For electrically-powered systems, significant spatial variation exists in the input fuel source-hydroelectric, nuclear, coal, oil, or natural gas-for the generation of electricity. Each of these sources produces a different mass of emissions per kWh generated. As such, it is necessary to know the source of electricity for the system being evaluated. Fortunately, in the United States and Canada, "typical" electricity sources are available based on location. Figure 1 shows North American Electric Reliability Corporation boundaries for the U.S. Each of these so-called "Coordinating Councils" (CC) reports the source composition for the electricity generated, from which typical emissions per kWh can be estimated. A similar, geographically based system exists in Canada.

FIGURE 1.

\section{U.S. electricity Coordinating} Council boundaries

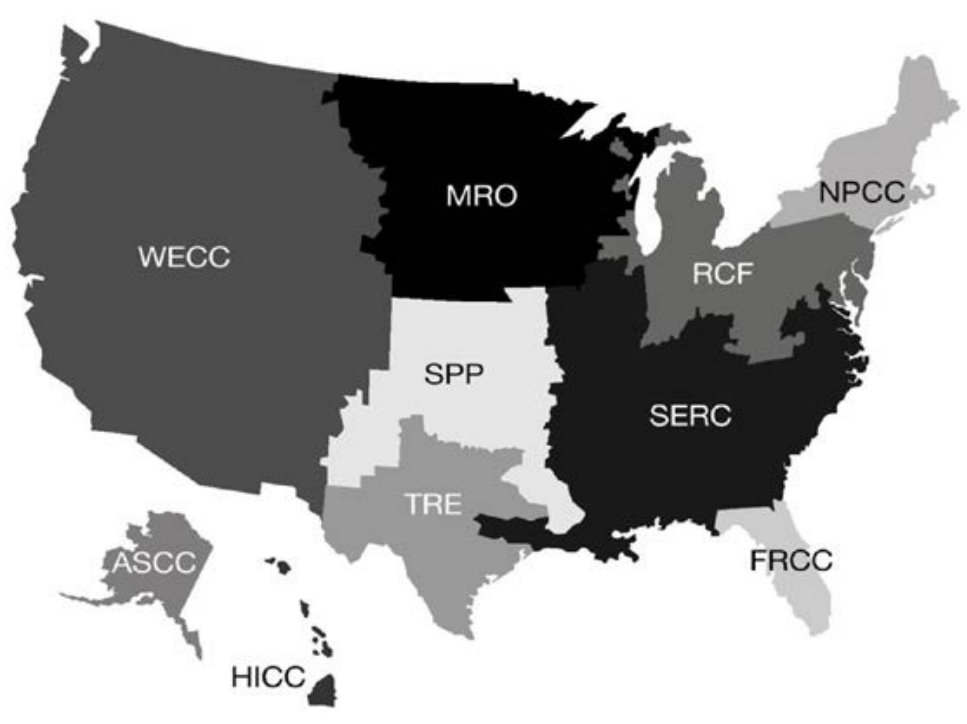


To incorporate this spatial component, the model asks the analyst to choose a country of analysis-currently limited to Canada and the United States. Once the country is chosen, a drop-down menu allows selection of the appropriate CC or geographic region, and the model then uses the relevant emissions data in ensuing calculations.

\section{Base Model Summary}

In Figure 2, we summarize the components and logic of the model. User inputs (dashed lines) related to the system include length, operating speeds, vehicle capacity, and analysis location. User inputs (double lines) for model parameters include energy consumption rates, energy costs, labor costs, and maintenance costs. Calculations done endogenously in the model (dotted lines) include the quantity of service provided, both annual vehicle hours and vehicle kilometers, as well as fleet size. From these functions, the model also computes annual labor, energy, and maintenance costs, as well as associated emissions. The final outputs of the model are the life cycle costs of each technology as well as their ratio, LRT costs/BRT costs.

FIGURE 2.

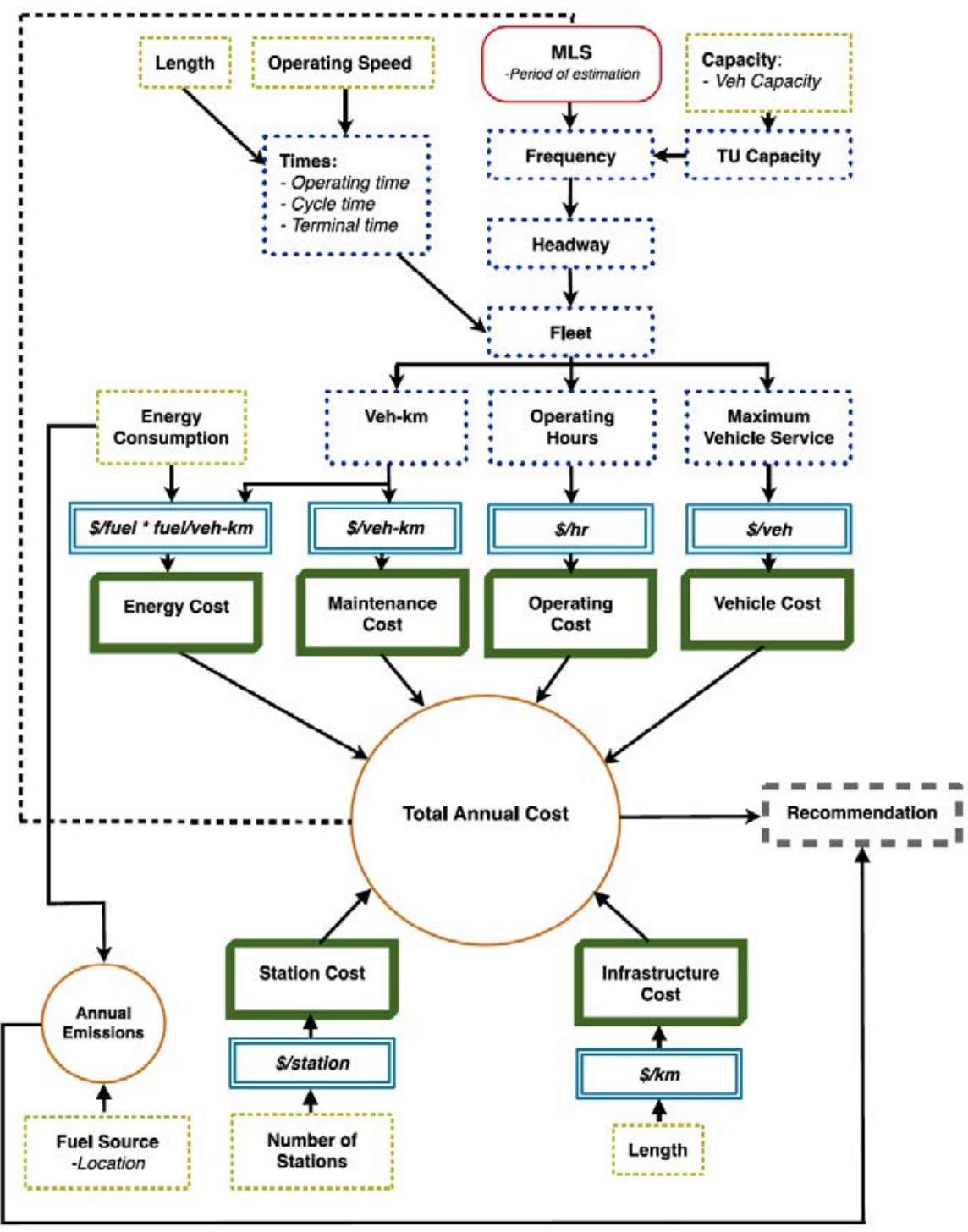




\section{Sensitivity Analysis}

The model is designed to conduct two types of sensitivity analysis. The first relates to demand and the second to operating parameters. For demand, we begin with the premise that for some levels of ridership, one technology will offer significantly lower costs and, absent other motivations, will clearly be the best choice. For example, if $P_{\max }$ were 50 passengers per hour, the operator would derive no benefit from higher-capacity vehicles and, as such, bus will nearly always present the lowest-cost alternative. On the other hand, if $P_{\max }$ were 10,000 passengers per hour, in nearly all cases, higher labor productivity will offset the higher investment costs for LRT to produce the lowest life-cycle alternative. But, depending on local parameters, there is a range of demand over which the life cycle costs for both technologies are very similar. If the estimated maximum demand falls into this range, then the analyst should be motivated to explore further sensitivities and to consider other, non-economic factors pertinent to the decision.

Our model identifies this "sensitivity range" by plotting annualized costs for both technologies as a function of demand. A sample output is shown in Figure 3, which illustrates the three decision domains. For low demand, BRT has the lowest life cycle costs, and for high demands, LRT has lower life cycle costs. In the range of demand between these two values - the sensitivity domain - the life cycle costs of the technology are sufficiently close that changes to the input assumptions may change the lower cost technology for a given demand level. The model presented here is able to generate these graphs by automatically computing actual annual life cycle costs as function of demand based on all system parameters.

FIGURE 3.

Life cycle costs as a function of demand

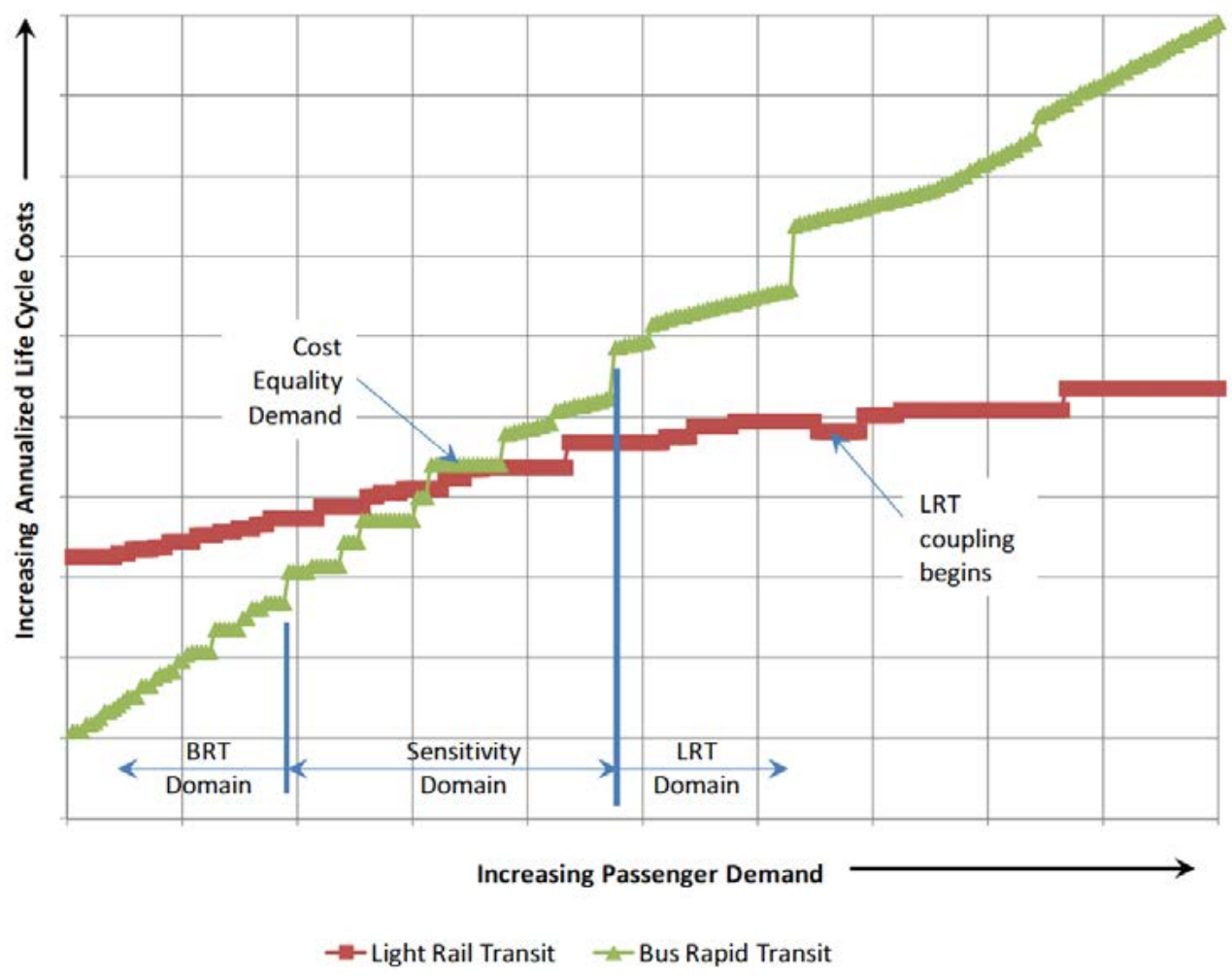


To understand the sensitivity of results to model parameters, we take the following approach. We present the user with a list of assumed parameters in the model. The user is then able to select those parameters on which sensitivity analysis is to be conducted. He then enters the range of values-deviations in \% from the current value-for each parameter. Finally, the user determines the number of intervals to be calculated between the current parameter value and the end points of the ranges.

Consider the case where labor costs are assumed to be $\$ 30$ per hour. The analyst may suspect that the actual labor rate may be between $\$ 25$ and $\$ 40$ per hour. As such, the analyst may use the model to calculate the life cycle costs of both technologies assuming labor costs of $\$ 25(\sim-16 \%), \$ 30, \$ 35(+16 \%)$, and $\$ 40(+33 \%)$. To make these calculations, the user simply specifies the range of $-16 \%$ to $+33 \%$ with $16 \%$ increments. Figure 4 shows the user interface for sensitivity analysis.

\begin{tabular}{|r|}
\hline \multicolumn{1}{|c|}{ Cost Parameters } \\
\hline Vehicle Capital Cost $(\$ / v e h)$ \\
\hline Infrastructure Construction Cost $(\$ / \mathrm{km})$ \\
\hline Station Construction Cost $(\$ / \mathrm{sta})$ \\
\hline Labour Cost $(\$ / \mathrm{hr})$ \\
\hline Labour Cost Growth Rate $(\%)$ \\
\hline Energy Consumption (kWh or L/ veh-km) \\
\hline Energy Cost $(\$ / \mathrm{kWh}$ or $\mathrm{L})$ \\
\hline Energy Cost Growth Rate $(\%)$ \\
\hline Vehicle Maintenance Cost $(\$ /$ veh-km) \\
\hline Infrastructure Maintenance Cost $(\$ / \mathrm{km})$ \\
\hline Maintenance Cost Growth Rate $(\%)$ \\
\hline
\end{tabular}

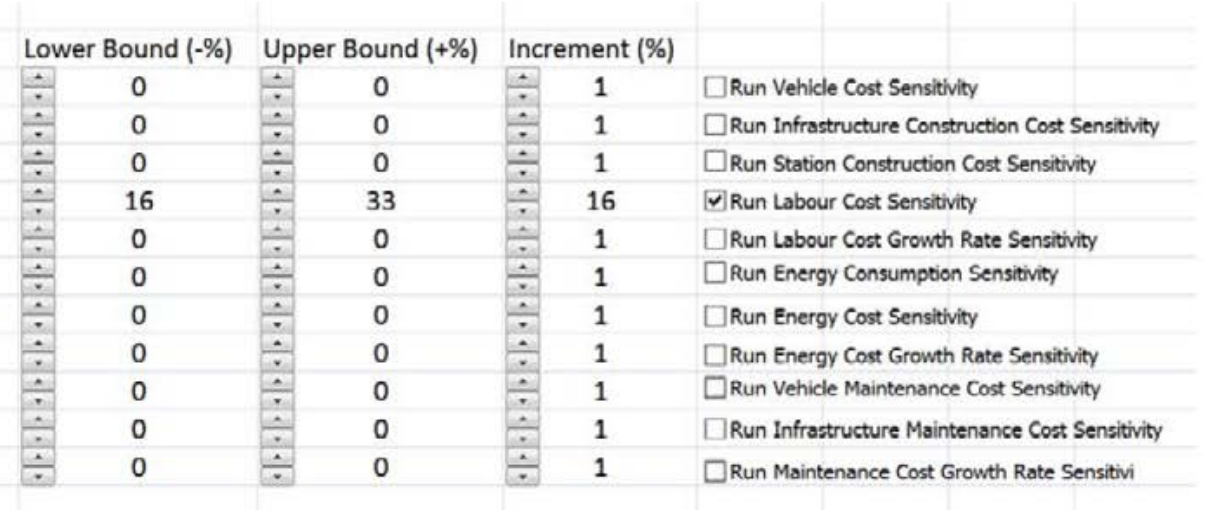

FIGURE 4. User interface for sensitivity analysis

Table 2 summarizes all the model components and units; it also identifies those variables that are available for sensitivity analysis. 
TABLE 2

All Model Components

\begin{tabular}{|c|c|c|c|}
\hline Model Component & Variable & Units & $\begin{array}{l}\text { Sensitivity } \\
\text { Test? }\end{array}$ \\
\hline \multicolumn{4}{|l|}{ Demand Variables } \\
\hline Maximum passenger demand in peak period & $P_{\max }$ & pass/hr & yes \\
\hline Duration of each period $j$ for which demand level is specified & Hoursj & hrs & \\
\hline Demand in non-peak periods, $j$ & $\beta j$ & $\%$ of $P \max$ & \\
\hline \multicolumn{4}{|l|}{ System Parameters } \\
\hline Line length & $L$ & $\mathrm{~km}$ & \\
\hline Operating speed & vo & $\mathrm{km} / \mathrm{hr}$ & yes \\
\hline Terminal time & $t_{t}$ & Min & \\
\hline Vehicle capacity & $c v$ & sps/veh & \\
\hline Capacity utilization coefficient & $\propto$ & pass/space & \\
\hline Vehicle spare ratio & spare & $\%$ & \\
\hline Number of stations & NSta & & \\
\hline Vehicle service life & $S L$ & yrs & yes \\
\hline Coupling (for headways $h<h c$ the model assumes LRT coupling) & $h c$ & $\min$ & \\
\hline \multicolumn{4}{|l|}{ Cost Parameters } \\
\hline Vehicle capital cost & VCC & $\$ /$ veh & yes \\
\hline Infrastructure construction cost & ICC & $\$ / \mathrm{km}$ & yes \\
\hline Station construction cost & SCC & $\$ /$ sta & yes \\
\hline Labor unit costs & $L R$ & $\$ / \mathrm{hr}$ & yes \\
\hline Energy consumption rate & $E C R$ & $\begin{array}{c}\mathrm{kWh} / \mathrm{km} \text { or } \\
\mathrm{L} / \mathrm{km}\end{array}$ & yes \\
\hline Energy unit costs & $E R$ & $\begin{array}{l}\$ / \mathrm{kWh} \text { or } \\
\$ / \mathrm{L}\end{array}$ & yes \\
\hline Vehicle maintenance unit costs & $V M R$ & $\$ / v e h-k m$ & yes \\
\hline Infrastructure maintenance unit costs & IMR & $\$ / \mathrm{km}$ & yes \\
\hline $\begin{array}{l}\text { Unit cost growth rates - annual change in unit costs for labor, } \\
\text { energy, and maintenance }\end{array}$ & $g k$ & $\%$ & yes \\
\hline \multicolumn{4}{|l|}{ Global Parameters } \\
\hline Period of study & $P$ & yrs & yes \\
\hline Interest rate-to discount future costs and revenues & $i$ & $\%$ & yes \\
\hline \multicolumn{4}{|c|}{ Endogenously Computed Variables } \\
\hline Frequency of service & $f$ & veh per hr & \\
\hline Cycle time & $T$ & hrs & \\
\hline Fleet size & $N$ & Veh & \\
\hline Annual labor hours & $L H$ & hrs & \\
\hline Annual vehicle kilometers & $V K m$ & veh-km & \\
\hline Annual energy consumption & $E$ & $\begin{array}{l}\text { kWh or } \\
\text { liters }\end{array}$ & \\
\hline
\end{tabular}




\section{Case Study}

The Province of Ontario, Canada, is expecting very large population increases leading up to 2031, particularly in an area known as the Greater Golden Horseshoe. The Province has designated some cities and regions to be target destinations-so-called "Places to Grow"-where major infrastructure investments will be made to manage increases in population. The Region of Waterloo, located approximately $100 \mathrm{~km}$ west of Toronto, is one of these Places to Grow. The Region's current population is about 553,000 but is expected to reach 731,000 residents by 2031. Similar growth is expected in the number of jobs (Region of Waterloo 2010). The Province of Ontario has mandated that the Region invest in infrastructure such that 40 percent of the forecast growth-houses and jobsare located in existing built-up areas.

To accommodate the increased transportation demand associated with this plan, the Region proposed a higher-order, longitudinally-separated public transit line to be operated with longer than typical station spacings along a central transit corridor. During the planning process, the Region and its consultants evaluated both BRT and LRT. After extensive debate, LRT was chosen. The project was approved in May 2012 (Region of Waterloo 2012).

Table 3 shows the input values assumed for the analysis. The values shown in bold are data from Regional planners. Those in normal font are estimated from data gathered from existing systems. (A more thorough explanation of the assumptions contained in Table 3, indicated by a superscript, is contained in notes following the paper.) 
TABLE 3. Assumed System and Cost Parameters for Case Study

\begin{tabular}{|c|c|c|}
\hline Model Component & LRT & BRT \\
\hline \multicolumn{3}{|l|}{ System Parameters } \\
\hline Line length $(\mathrm{km})$ & 19 & 19 \\
\hline Operating speed $(\mathrm{km} / \mathrm{hr})$ & 30 & 30 \\
\hline Terminal time $(\mathrm{min})$ & 5 & 5 \\
\hline Vehicle capacity (spaces/veh) & 222 & 90 \\
\hline Capacity utilization coefficient (pass/space) & 0.8 & 0.9 \\
\hline Vehicle spare ratio (\%) & 10 & 10 \\
\hline Number of stations & 15 & 15 \\
\hline Vehicle service life (yrs) & 30 & 12 \\
\hline Coupling & $h<=5 \mathrm{~min}$ & $\mathrm{~N} / \mathrm{A}$ \\
\hline \multicolumn{3}{|l|}{ Cost Parameters } \\
\hline Vehicle capital cost $(\$ \mathrm{~m})$ & 4.50 & 0.75 \\
\hline Infrastructure construction cost $(\$ \mathrm{~m} / \mathrm{km})^{1}$ & 39.70 & 11.80 \\
\hline Station construction cost $(\$ \mathrm{~m} / \mathrm{sta})^{2}$ & 2.20 & 0.66 \\
\hline Labor unit costs $(\$ / \mathrm{hr})$ & 40.00 & 40.00 \\
\hline $\begin{array}{l}\text { Energy consumption rate: } \\
(\mathrm{kwh} / \mathrm{km})^{3} \\
(\mathrm{l} / \mathrm{km})\end{array}$ & 8.3 & 1.0 \\
\hline $\begin{array}{l}\text { Energy unit costs: } \\
(\$ / k w h)^{4} \\
(\$ / l)\end{array}$ & 0.09 & 1.20 \\
\hline Vehicle maintenance unit costs $(\$ / \mathrm{veh}-\mathrm{km})^{5}$ & 0.50 & 0.30 \\
\hline Infrastructure maintenance unit costs $(\$ \mathrm{~m} / \mathrm{km})^{6}$ & 0.120 & 0.05 \\
\hline Labor cost growth rate $(\% / y r)^{7}$ & 5.80 & 5.80 \\
\hline Energy cost growth rate $(\% / y r)^{8}$ & 6.50 & 6.00 \\
\hline Maintenance cost growth rate (\%/yr) & 2.50 & 2.50 \\
\hline \multicolumn{3}{|l|}{ Global Parameters } \\
\hline Period of study & 40 & 40 \\
\hline Interest rate - to discount future costs and revenues & 3.0 & 3.0 \\
\hline
\end{tabular}

Note: Values in bold provided directly from Region of Waterloo or its consultants.

\footnotetext{
${ }^{1}$ The infrastructure costs for the proposed LRT are shown in the following table. The total LRT cost (excluding vehicle acquisition and station construction) is $\$ 719 \mathrm{M}$. An equally detailed estimate for BRT was not available. As such, we took the following approach to estimate BRT costs. We assumed that the construction of BRT would incur a proportion of the LRT costs. For example, we assume that BRT will require the same property allocation as LRT and, therefore, the property allocation costs are equal between modes; the proportion, therefore, is 1.0. In contrast, BRT systems require no electrification, so that proportion is listed as 0 . Each assumed cost and the resulting cost per kilometer is shown at the bottom of the next page.
} 
The proposed system will be built in two phases. The first section of the system, planned to open in 2017, will include $19 \mathrm{~km}$ of LRT with a so-called Adapted Bus Rapid Transit (aBRT) system - a system that includes transit signal priority, some queue jump lanes, longer station spacings, and real-time information-for an additional $17 \mathrm{~km}$. The second phase of the project will convert the aBRT system to LRT. No firm timetable has been established for that conversion. In our analysis, we analyze the first phase, comparing LRT and BRT over 19 $\mathrm{km}$ with 15 stations. The system operating speed is estimated at $30 \mathrm{~km} / \mathrm{hr}$.

The Region's LRT vehicle holds 222 passengers, with normal loading standards at 80 percent of this value. Similarly, the BRT vehicle has a maximum capacity of 90 persons, but an operating level at 90 percent. In each case, the fleet size should include 10 percent spares. LRT vehicles are assumed to last 30 years, whereas BRT vehicles have a service life of 12 years. The LRT vehicle costs approximately $\$ 4.5 \mathrm{M}$; the BRT vehicle costs about $\$ 0.75 \mathrm{M}$. For LRT, we assume that coupling will occur when demand warrants single-vehicle headways shorter than five minutes.

Assumed Relationships between LRT and BRT Costs

\begin{tabular}{|l|c|c|c|l|}
\hline Cost Component & $\begin{array}{c}\text { LRT } \\
\text { Estimate }\end{array}$ & $\begin{array}{c}\text { Proportion of } \\
\text { Cost for BRT }\end{array}$ & $\begin{array}{c}\text { BRT } \\
\text { Cost }\end{array}$ & Explanation \\
\hline Engineering/EA, etc. & $\$ 245 \mathrm{M}$ & 0.20 & $\$ 49 \mathrm{M}$ & Development of BRT contract plans far less sophisticated than LRT \\
\hline Civil Costs & $\$ 188 \mathrm{M}$ & 0.15 & $\$ 28 \mathrm{M}$ & Far less civil infrastructure required for BRT than LRT \\
\hline Electrification & $\$ 90 \mathrm{M}$ & 0.00 & 0 & No electrification necessary \\
\hline Utility relocation & $\$ 98 \mathrm{M}$ & 0.80 & $\$ 78 \mathrm{M}$ & Similar utility relocations necessary regardless of technology \\
\hline Maintenance facility & $\$ 49 \mathrm{M}$ & 0.50 & $\$ 24 \mathrm{M}$ & Less sophisticated maintenance facility; local expertise in place \\
\hline Structures & $\$ 25 \mathrm{M}$ & 0.80 & $\$ 20 \mathrm{M}$ & Similar structures required regardless of technology \\
\hline Property allocation & $\$ 25 \mathrm{M}$ & 1.00 & $\$ 25 \mathrm{M}$ & $\begin{array}{l}\text { BRT has wider alignment requirements; this represents a lower } \\
\text { bound on BRT property allocation costs }\end{array}$ \\
\hline Total & $\$ 719 \mathrm{M}$ & & $\$ 224 \mathrm{M}$ & \\
\hline Cost $/ \mathrm{km}$ & $\$ 37.9 \mathrm{M}$ & & $\$ 11.8 \mathrm{M}$ & \\
\hline
\end{tabular}

${ }^{2}$ The cost of station construction for LRT is estimated at $\$ 33 \mathrm{M}$, or $\$ 2.2 \mathrm{M}$ per station. As with Note 1 above, no formal estimate of BRT costs was available. We assume BRT stations cost $30 \%$ of LRT stations, or $\$ 0.66 \mathrm{M} /$ station.

${ }^{3}$ The electricity consumption rate is derived from APTA's Public Transportation Factbook. In 2011, LRT systems in the United States consumed $750.4 \mathrm{M} \mathrm{kWh}$ of electricity in operating 90.7 veh- $\mathrm{km}$. This ratio is approximately $8.3 \mathrm{kWh} / \mathrm{veh}-\mathrm{km}$. The data are available at http://www.apta.com/resources/statistics/Documents/FactBook/APTA_2011_Fact_Book.pdf The diesel consumption rate is derived from Grand River Transit operating data.

${ }^{4}$ Energy cost per kWh is derived from the three-year averages of five U.S. systems: Houston, Dallas, Sacramento, Salt Lake City, and Denver. These data are available at http://www.ntdprogram.gov/ntdprogram/. The cost per liter of diesel fuel is taken from Grand River Transit operating data.

5,6 The vehicle and infrastructure maintenance costs for LRT vehicles are derived from the three-year averages of five U.S. systems: Houston, Dallas, Sacramento, Salt Lake City, and Denver. These data are available at http://www.ntdprogram.gov/ntdprogram/. The BRT vehicle maintenance costs are from 2010 GRT operating data.

${ }^{7}$ The growth in labor costs is computed from the average year-over-year increase in labor expenses at GRT in the period from 2003 to 2010 .

${ }^{8}$ The growth in energy costs is computed as the average year-over-year increase in diesel and electricity prices from November 2005 to November 2013. Data for diesel are available at http://www.energy.gov.on.ca/en/fuel-prices/, Data for electricity are available at http://www.ontarioenergyboard.ca/OEB/Consumers/Electricity/Electricity\%20Prices/Historical\%20Electricity\%20Prices. 
The alignment capital costs are about $\$ 40 \mathrm{M}$ per kilometer for LRT and about $\$ 12 \mathrm{M}$ per kilometer for BRT. For stations, the average cost of an LRT station for the proposed system is $\$ 2.2 \mathrm{M}$; this value is heavily influenced by a proposed transit hub that includes a grade-separated (underground) platform connected to a mixed-use development. The BRT stations are considerably less expensive, estimated at 30 percent of the LRT costs, or $\$ 0.66 \mathrm{M}$. These values are consistent with other system data in the literature (Casello and Vuchic 2009).

The operating costs parameters used in the model are largely derived from existing systems' performance. For LRT systems' energy consumption, vehicle maintenance, and infrastructure maintenance, we use data from the National Transit Database (NTD) for similar, currently-operating systems to generate estimates. For BRT systems, we use actual costs from the local transit system (Grand River Transit) whenever possible. We chose to evaluate the technologies over a 40-year time period, with a base assumption of 3.0 percent interest rates.

The demand profile is shown in Figure 5. The system will operate for 18.5 hours per day, with 5.0 hours of peak demand, 9.5 hours of mid-level demand ( $80 \%$ of peak), and 3.0 hours of low demand ( $60 \%$ of peak). Regional planners estimate a value of Pmax of 1,665 persons per hour during peak periods.

FIGURE 5.

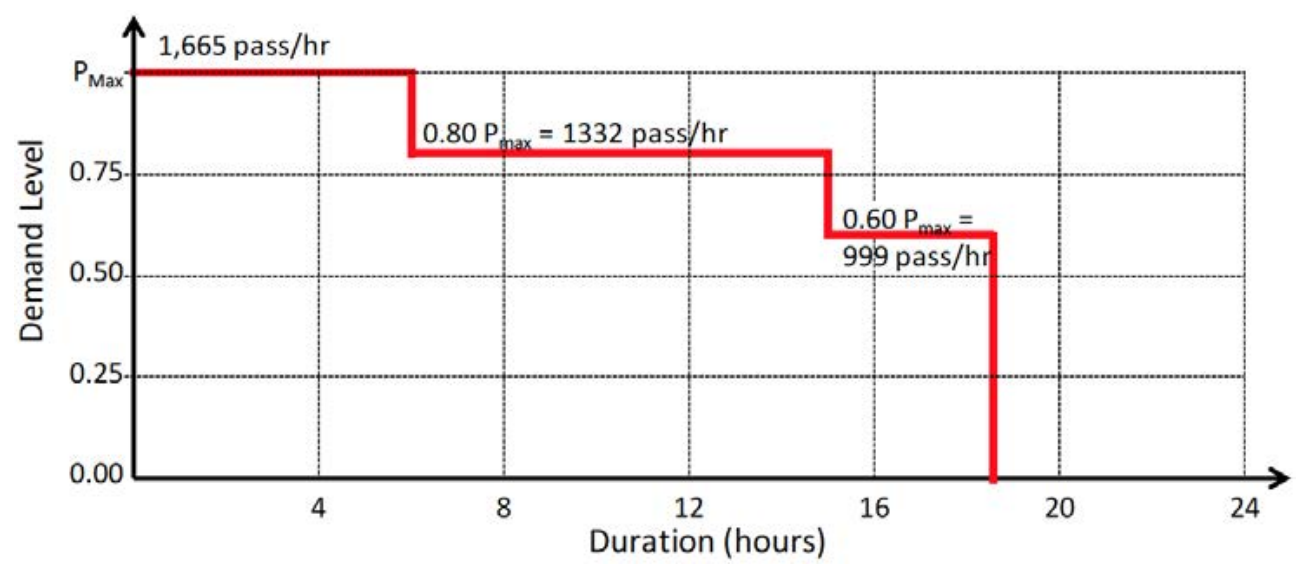

\section{Results and Discussion}

The data presented in Table 2 and Figure 5 were entered into the model. As noted previously, the model first calculates the required frequency of service for each demand period. From these frequencies, the model also calculates the number of vehicle hours and vehicle kilometers traveled, from which annual labor and fuel costs can be directly quantified. The model outputs for operations-labor hours, vehicle kilometers, and energy consumed-and their respective costs are shown in Table 4. 
TABLE 4.

Model Life Cycle Outputs for Operations and Operating

Costs

\begin{tabular}{|l|c|c|}
\hline \multicolumn{1}{|c|}{ Component } & LRT & BRT \\
\hline Peak service frequency (veh/hr) & 10 & 24 \\
\hline Peak service headway (min/veh) & 6.0 & 2.5 \\
\hline Annual labor hours & 76,636 & 184,059 \\
\hline Annual vehicle kilometers & $1,388,900$ & $3,424,370$ \\
\hline Annual energy consumption & $11,527 \mathrm{MWh}$ & $3.4 \mathrm{ML}$ \\
\hline Annualized labor costs (\$millions) & $\$ 9.11$ & $\$ 21.88$ \\
\hline Annualized energy costs (\$millions) & $\$ 3.52$ & $\$ 11.70$ \\
\hline Annualized maintenance cost (\$millions) & $\$ 7.72$ & $\$ 5.38$ \\
\hline Total annual operating cost (\$millions) & $\$ 20.35$ & $\$ 38.96$ \\
\hline
\end{tabular}

To verify the model's output, we compare the results for the first year of operation in the Waterloo case to operating LRT systems in the US using 2012 system data. The results are shown in Table 5.

TABLE 5.

Comparison of

Waterloo Data and

Operating U.S.

LRT Systems

\begin{tabular}{|l|r|r|r|r|r|c|}
\hline & Houston & Waterloo* & Dallas & Salt Lake City & Denver & Sacramento \\
\hline System length $(\mathrm{km})$ & 29.3 & 19.0 & 282.3 & 114.7 & 116.6 & 120.9 \\
\hline Number of vehicles & 18 & 17 & 100 & 82 & 102 & 61 \\
\hline Vehicle-hours / year & 76,596 & 76,636 & 381,882 & 466,244 & 449,030 & 195,769 \\
\hline Vehicle-km/year (000s) & 1,469 & 1,389 & 12,300 & 9,607 & 14,380 & 6,325 \\
\hline 2012 Operating labor costs (\$000s) & 6,123 & 2,755 & 42,929 & 11,003 & 17,840 & 15,100 \\
\hline 2012 Total maintenance costs (\$000s) & 8,576 & 6,033 & 39,770 & 15,132 & 20,298 & 12,096 \\
\hline 2012 Energy costs (\$000s) & 615 & 1,038 & 13,858 & 5,010 & 5,961 & 4,056 \\
\hline
\end{tabular}

* Operating cost values for Waterloo are for first year of operation.

The data in Table 5 suggest that the model estimates are consistent with actual data from currently operating systems. When comparing Houston and Waterloo, the two most similar systems in service provision, one can observe that the operating costs are much less in Waterloo. This is primarily a result of higher labor costs in the U.S. due to the provision of health care benefits. In Houston, base labor costs are about \$3.9M per year, with an addition $\$ 2.2 \mathrm{M}$ in "fringe benefits." Despite this difference, this comparison suggests that the initial assumption for hourly labor rate in Waterloo is somewhat low. Maintenance costs and energy costs are sufficiently similar to give confidence in the model's outputs.

The model output for capital and total costs is shown in Table 6. For LRT vehicles, the model computes the cost of purchasing a fleet of 17 vehicles in year 0 and again at the end of the first fleet's service life, in year 30. For BRT, a fleet of 39 buses is necessary in years 0 , 12,24 , and 36 . The costs of these purchases are converted to annualized costs. The total infrastructure cost for both technologies is annualized over the 40-year period. 
TABLE 6.

Model Estimates for Capital and Total Costs (\$Millions)

\begin{tabular}{|l|r|r|}
\hline \multicolumn{1}{|c|}{ Component } & \multicolumn{1}{c|}{ LRT } & \multicolumn{1}{c|}{ BRT } \\
\hline Vehicle fleet size & 17 & 39 \\
\hline Annualized vehicle cost & $\$ 4.67$ & $\$ 3.25$ \\
\hline Annualized infrastructure cost & $\$ 31.16$ & $\$ 9.70$ \\
\hline Annualized station costs & $\$ 1.43$ & $\$ 0.43$ \\
\hline Total annualized capital cost & $\$ 37.26$ & $\$ 13.34$ \\
\hline Total annual operating costs & $\$ 20.35$ & $\$ 38.96$ \\
\hline Total annual cost & $\$ 57.61$ & $\$ 52.30$ \\
\hline Ratio of annual costs (LRT/BRT) & \multicolumn{3}{|c|}{1.10} \\
\hline
\end{tabular}

Based on these data, the Region has selected the alternative with the higher life cycle cost over this analysis period with the input assumptions. The LRT model will cost approximately $\$ 57.6 \mathrm{M}$ per year annually, whereas the BRT system will cost $\$ 52.30 \mathrm{M}$ per year. The two technologies appear to have equal cost at a maximum load section demand of about 2300 passengers per hour, approximately 40 percent higher than the forecasted demand. This suggests that other considerations have influenced the ultimate decision. One such consideration is the quantity of emissions produced.

Table 7 shows the annual $\mathrm{NO}_{x}, \mathrm{SO}_{2}$, and $\mathrm{CO}_{2}$ emissions for each of the technologies. For LRT, the emission quantities are based on the current methods for producing electricity, which in Ontario currently include hydroelectric, nuclear, coal (though this is being phased out), and a small proportion of renewables.

TABLE 7.

\begin{tabular}{|c|r|r|r|}
\hline $\begin{array}{c}\text { Annual Emissions } \\
\text { (metric tonnes) }\end{array}$ & \multicolumn{1}{c|}{ LRT } & \multicolumn{1}{c|}{ BRT } & \multicolumn{1}{c|}{$\begin{array}{c}\text { Ratio } \\
\text { LRT/BRT }\end{array}$} \\
\hline $\mathrm{NO}_{\mathrm{x}}$ & 3.85 & 7.01 & 0.55 \\
\hline $\mathrm{SO}_{2}$ & 5.77 & 8.85 & 0.65 \\
\hline $\mathrm{CO}_{2}$ & $2,044.73$ & $2,287.40$ & 0.89 \\
\hline
\end{tabular}

From an environmental perspective, the electrically-powered LRT vehicles produce fewer emissions-55, 65, and 89 percent for $\mathrm{NO}_{x}, \mathrm{SO}_{2}$, and $\mathrm{CO}_{2}$, respectively - when compared to BRT. These emissions data provide an additional, currently unmonetized and increasingly important consideration in selecting technology.

\section{Sensitivity to Inputs}

As noted earlier, technology selection depends heavily on the assumed level of demand. To demonstrate this relationship for the Waterloo example, we plot the total annual cost for each technology as a function of demand. This is shown in Figure 6. For the Waterloo system parameters, a demand less than 1,520 produces costs ratios (LRT/BRT) greater than 1.20. Typically, for a ratio of this magnitude, it would be difficult to justify the additional annualized life cycle cost of LRT. Similarly, for demands above 3,020 passengers per hour, the ratio falls below 0.83 , indicating LRT is significantly less expensive. Most interestingly, there exists a large range of demand-from 1,520 to 3,020 passengers per hour-for which the ratio of annualized costs varies from only 1.14 to 0.98 . This suggests that for demands in this range, which includes the estimated demand for the Waterloo case of 
1,665 passengers per hour, substantial sensitivity analysis and heightened consideration of "secondary" project goals are warranted.

FIGURE 6.

Modal domains based on Waterloo system data

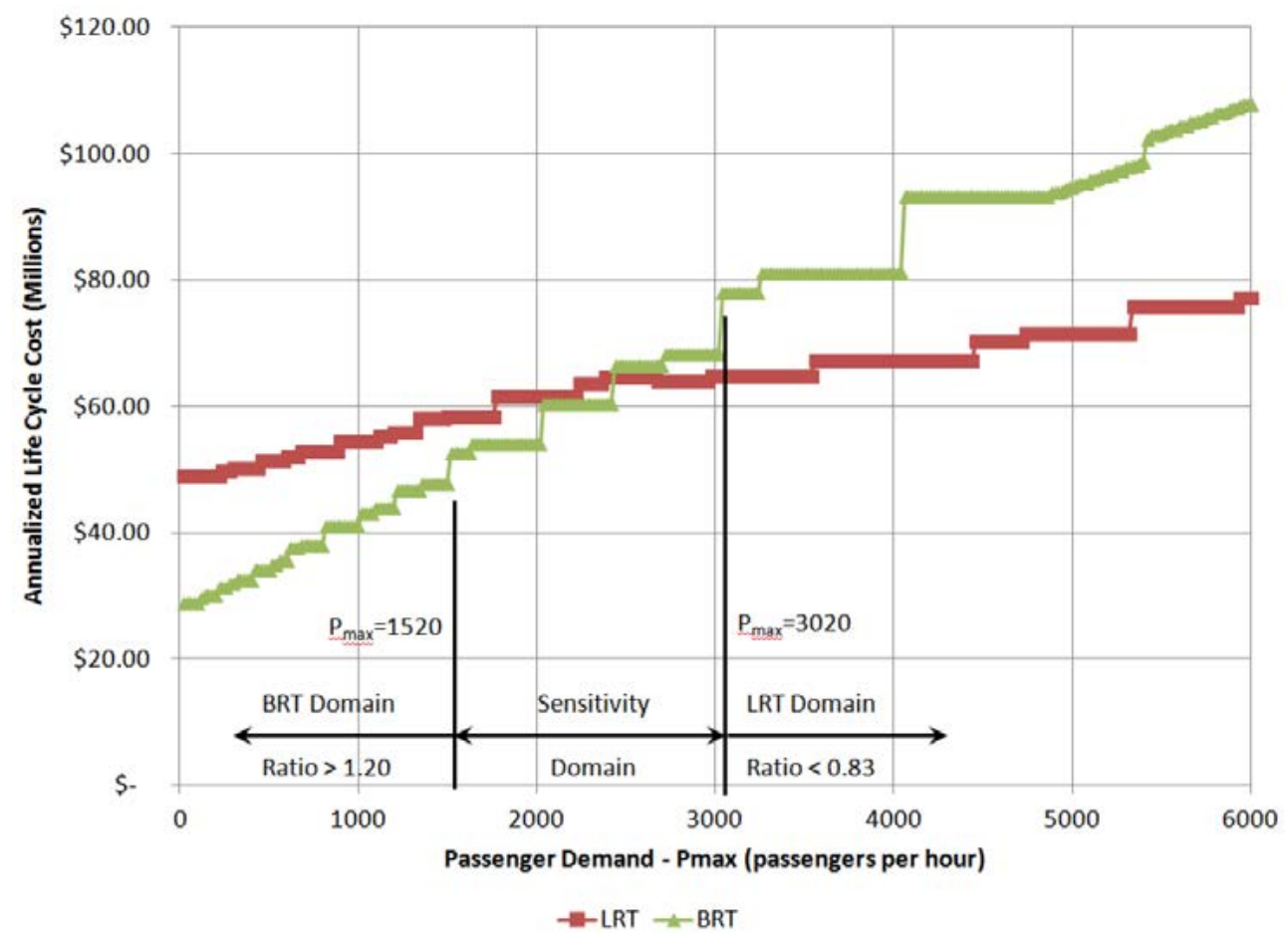

To this end, we varied many input parameters over a "reasonable" range of values to determine the sensitivity of the technology selection to the input assumptions. We first evaluated the model over a range of values for the global variables-interest rates and study period. For each, we calculated the ratio of LRT to BRT costs for values between -50 and +50 percent of the original assumption. So the model is solved for study periods ranging from 20 to 60 years; for interest rates, the model is solved from 1.5 to 4.5 percent. The results are shown in Figure 7. 
FIGURE 7.

Technology selection sensitivity to global parameters

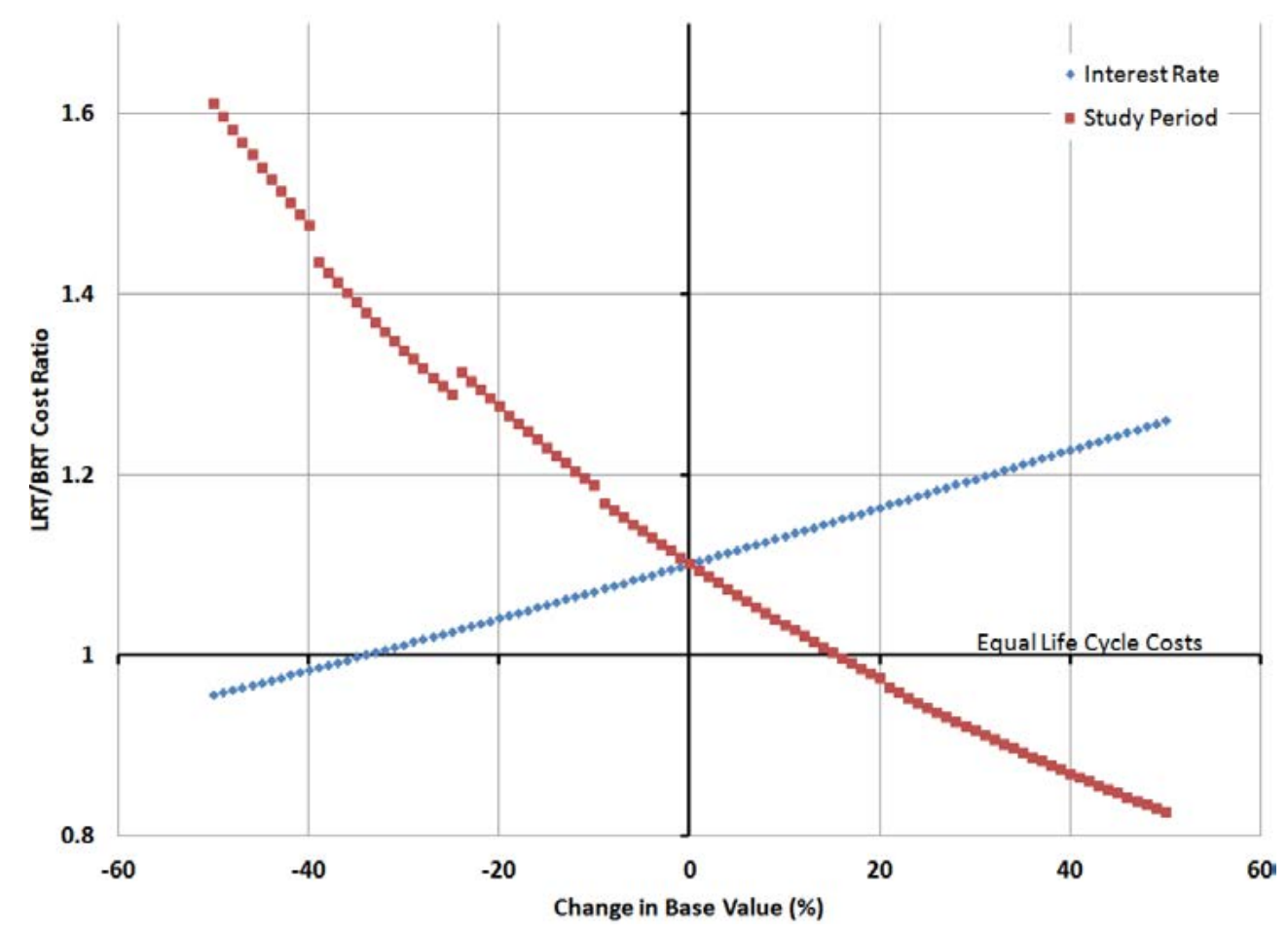

This diagram demonstrates that the technology selection is particularly sensitive to these global variables. If the project is evaluated over 48 years (a $20 \%$ increase on the assumed 40-year analysis period), then the LRT design is lower cost. If the interest rate for the project is actually only 1.8 percent over the 40 -year period, LRT once again becomes the less expensive option. A longer study period favors LRT because the higher investment cost is annualized over a longer period. Similarly, higher interest rates translate into higher annual costs for the initial investments.

For operating parameters-labor costs, energy costs, and maintenance costs-we solved the model with simultaneous changes to both technologies over the same range of values, from -50 to +50 percent. The results, shown in Figure 8, demonstrate importance of labor costs in comparing these two technologies. For labor values greater than about $\$ 56 / \mathrm{hr}$ ( $40 \%$ above the assumed $\$ 40 / \mathrm{hr}$ ), the technology selection changes. The model shows some sensitivity to energy costs, but the choice of technology does not change over the test range. Technology selection is decidedly insensitive to maintenance costs, both vehicle and infrastructure. We also calculated the impacts of operating parameters' growth rates over the same range. The results are very similar to those shown in Figure 8, though the model is slightly more sensitive to growth in energy costs. 
FIGURE 8.

Sensitivity to operating cost assumptions

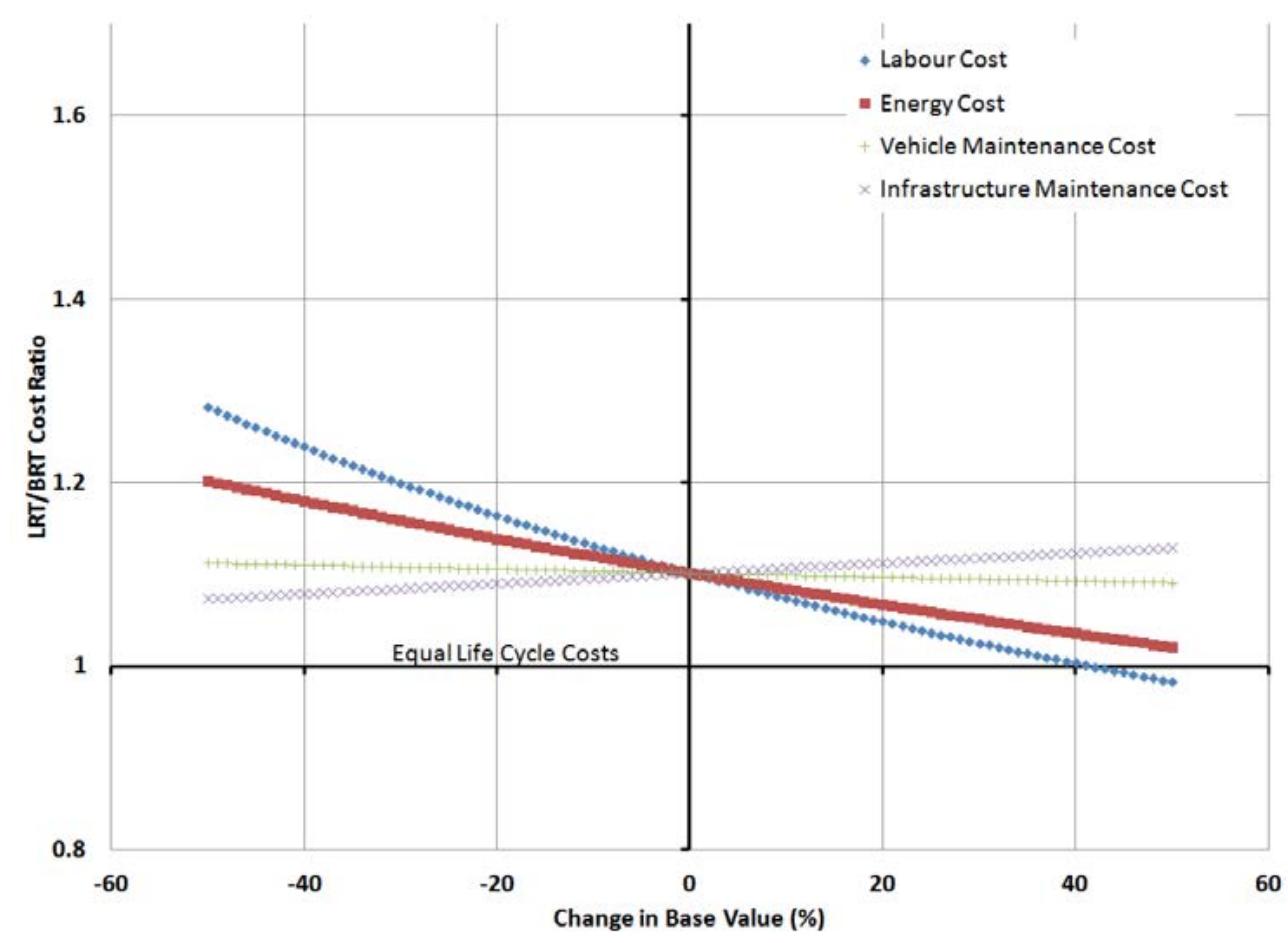

Finally, we tested the model's sensitivity to infrastructure costs, both vehicle and alignment. The results show that technology selection is far more sensitive to alignment costs than to vehicle costs-a logical outcome given the magnitude of the two costs. Figure 9 shows that if each alignment costs are reduced by approximately 25 percent, then LRT becomes less expensive.

FIGURE 9.

Sensitivity to infrastructure costs

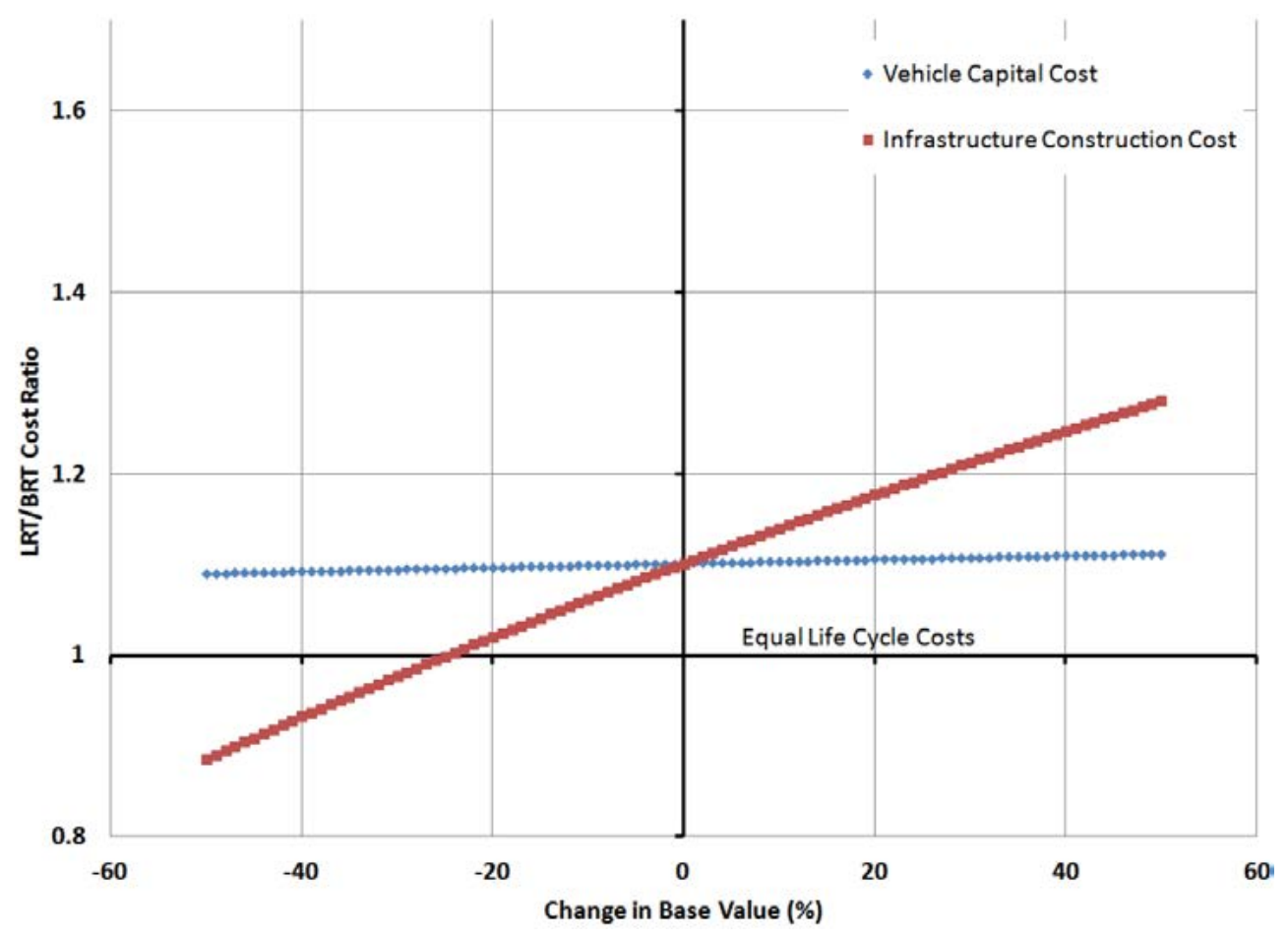


To summarize the sensitivity, Table 8 shows values at which LRT becomes the less expensive technology for applicable inputs-those inputs for which no change in technology is observed over the sensitivity range are omitted.

TABLE 8.

Values for Inputs at which Optimal Technology Choice Changes

\begin{tabular}{|l|c|c|c|c|}
\hline & \multicolumn{2}{|c|}{ Default Values } & \multicolumn{2}{c|}{ Cost Equality Values } \\
\hline Input variable & LRT & BRT & LRT & BRT \\
\hline Operating speed & $30 \mathrm{~km} / \mathrm{hr}$ & $30 \mathrm{~km} / \mathrm{hr}$ & $22.6 \mathrm{~km} / \mathrm{hr}$ & $22.6 \mathrm{~km} / \mathrm{hr}$ \\
\hline Labor cost & $\$ 40 / \mathrm{hr}$ & $\$ 40 / \mathrm{hr}$ & $\$ 56.40 / \mathrm{hr}$ & $\$ 56.40 / \mathrm{hr}$ \\
\hline Interest rate & $3.00 \%$ & $3.00 \%$ & $2.24 \%$ & $2.24 \%$ \\
\hline Study period & $40 \mathrm{yrs}$ & $40 \mathrm{yrs}$ & $46 \mathrm{yrs}$ & $46 \mathrm{yrs}$ \\
\hline Infrastructure cost & $\$ 37.9 \mathrm{M} / \mathrm{km}$ & $\$ 11.8 \mathrm{M} / \mathrm{km}$ & $\$ 30.6 \mathrm{M}$ & $\$ 9.5 \mathrm{M}$ \\
\hline Energy cost growth rate & $6.4 \%$ & $5.6 \%$ & $9.15 \%$ & $8.01 \%$ \\
\hline
\end{tabular}

\section{Impacts of High Capacity Bus Systems and Alternative Technologies}

In many developing countries, high transit ridership is accommodated using articulated and bi- articulated transit vehicles. Vehicle capacities for these systems approach and, in some cases, exceed rail vehicle capacities. For example, Reilly and Levinson (2012) report vehicle capacities ranging from 160 to 260 persons per vehicle depending on the assumptions about loading standards. Naturally, these double-articulated vehicles significantly increase labor productivity and, as a result, lower the annual operating hours compared to conventional buses.

Mexico City operates Volvo bi-articulated vehicles on the Insurgentes line, where the demand on the maximum load section is 9,000 passengers per hour per direction. Following Reilly and Levinson (2012), we assume a vehicle loading of 217 persons per vehicle. To accommodate demand, buses must be operated with a frequency of about 50 vehicles per hour, the approximate functional upper bound for bus systems in the absence of overtaking or double-berthing at stations (Brunn 2005). In contrast, two coupled LRT vehicles can be operated as a transit unit with a frequency of about 30 per hour. Three-car LRT transit units could be operated with three-minute headways (20 per hour) without significantly decreasing passenger attraction.

The result is that buses still require approximately double (or triple) the number of operator hours to meet the demand observed in Mexico City compared to rail systems. But, in Mexico City as in most developing countries, labor rates are very low compared to North America. As a result, the annual labor savings from rail are far less important in the analysis than the differences in capital investments. Obviously, the Mexico City line does not require electrification or civil infrastructure to facilitate rail operations. Further, while the cost of bi-articulated vehicles is marginally higher than conventional buses-approximately $\$ 700,000$ per vehicle (COST 2011) - these costs remain significantly less than rail vehicles. The station infrastructure, however, is designed to accommodate off-board fare collection and high platform boardings. As such, these station infrastructure costs will be comparable to light rail stations.

On the whole, the combination of very high labor productivity and low labor costs tend to make BRT systems the lower-cost alternatives for even very high demand in developing 
countries. The model presented here allows the analyst to determine the levels of demand that warrant further investigation between two technologies and to easily conduct sensitivity analysis. In Mexico City, or, more generally, in the developing world, the appropriate technology may be most sensitive to growing labor rates or changes in energy costs.

Battery electric buses promise the best characteristics of LRT and BRT options: the low infrastructure cost of BRT combined with the zero (point source) vehicle emissions of LRT (electric trolley bus systems also have zero vehicle emissions like LRT, but infrastructure costs are between BRT and LRT due to electrification). There are two technical hurdles currently limiting the realization of this promise. First is the issue of operating range. Energy density and mass characteristics of current battery technologies result in undesirably short vehicle range, given the battery mass and volume a transit vehicle is able to carry. The second issue is related to the life cycle impacts of battery systems. There are significant impacts associated with the production and end-of-life (recovery and recycling) of current battery technologies, many of which also rely on strategic materials such as lithium (Majeau-Bettez et al. 2011). Wide-scale deployment of batteries in transit (and private vehicles) will strain supplies of these materials, resulting in increases in both vehicle cost and battery replacement cost during a vehicle's lifetime. Until these two hurdles are overcome, battery electric buses will likely be restricted to applications characterized by short route length and a requirement for zero vehicle emissions.

The model framework we present accounts for capital costs, operating costs, and operating emissions, but does not directly account for the life cycle impacts of batteries. As such, if battery electric vehicles are considered, then an additional assessment of the battery technology will be required. This evaluation is certainly a potential addition to the base model presented here.

\section{Conclusion and Future Research}

The overarching goals of this research are to create a tool that assists in technology selection based on life cycle costs and emissions and to demonstrate that the choice of technology is quite sensitive to input assumptions. In our case study, a bus system has a lower economic cost, but higher emissions with the default values. The expected demand for the system $-1,665$ passengers per hour-is within a sensitivity domain where the LRT/ BRT cost ratio is sufficiently close to 1.0 to warrant further exploration. The model allows for this sensitivity to be tested easily. In our case, if the project was evaluated over 46 years, rather than 40 , the LRT would be less expensive.

Similarly, if labor rates were to increase to $\$ 56$ per hour-a value observed in other operating systems-or the interest rate falls to 2.2 percent over the analysis period, LRT is less expensive.

There are several logical extensions to this model. First, more technologies can be added to the comparison, including metro and some automated systems. Second, the emissions module can be extended to include electricity sources for regions outside of North America. As markets evolve for emissions trading, the costs of different emissions can be included in the overall economic assessment of the modes. The authors are eager to work with practitioners and transit agencies on the application and further development of the model. 


\section{Acknowledgments}

The authors wish to thank transit planners from the Regional Municipality of Waterloo for their assistance in the development of the model and for the provision of data, including ridership forecasts and capital and operating cost estimates for both LRT and existing bus service.

\section{References}

Allport, R. J. 1981. The costing of bus, light rail transit, and metro public transport systems. Traffic Engineering and Control 22: 633-639.

American Public Transportation Association (APTA). 2010. Operating a bus rapid transit system. BRT Operations Working Group. APTA Standards Development Program, Washington, DC.

Baukal, C. 2005. Everything you need to know about NOx. Pollution Control.

Brunn, E. 2005. Bus rapid transit and light rail: Comparing operating costs with a parametric cost model. Transportation Research Record 1927: 11-21.

Casello, J. M., and V. R. Vuchic. 2009. Urban transit, Chapter 16. In Meyer, M. ed. Transportation Planning Handbook, 3rd Edition. Institute of Transportation Engineers, Washington, DC.

Chester, V. M., A. Horvath, and S. Madanat. 2010. Comparison of life-cycle energy and emissions footprints of passenger transportation in metropolitan regions. Atmospheric Environment 44: 1071-1079.

City of Calgary. About Calgary Transit: LRT technical data. Calgary Transit. Available at http://www.calgarytransit.com/html/technical_information.html, accessed 2011.

COST. 2011. Buses with high level of service. European Science Foundation. Retrieved from http://www.uitp.org/sites/default/files/cck-focus-papers-files/BHLS_COST_ final_report_October2011.pdf.

CUTA. 2007. Bus rapid transit: A Canadian perspective. Canadian Urban Transit Association 25, CUTA, Toronto, ON.

CUTA. 2011. Canadian transit fact book: 2010 operating data. Canadian Urban Transit Association, Toronto, ON.

Danaher, A. R. 2009. What is BRT? BRT Seminar. City of Madison/Madison Transit, October 1.

Edwards, M., and R. L. Mackett. 1996. Developing new urban public transport systems process, Transport Policy 3(4): 225-239.

EIA. 2012. Annual electric power industry report. U.S. Energy Information Administration, retrieved at <http://www.eia.gov/electricity/data/eia861/index.html>, accessed October 10, 2012. 
Gordon, P. (1999). Improving transportation in the San Fernando Valley. Retrieved from http://trid.trb.org/view.aspx?id=579792.

Griswold, J. B., S. Madanat, and A. Horvath. 2013. Tradeoffs between costs and greenhouse gas emissions in the design of urban transit systems. Environmental Research Letters 8(4), 044046. doi:10.1088/1748-9326/8/4/044046.

Hammonds, S. 2002. Light rail in Calgary and Edmonton. Peace and Environment News, Sept. Retrieved from http://207.112.105.217/PEN/2002-09/s- hammonds.html, accessed October 12, 2012.

Hemily B., and R. King. 2003. TCRP Synthesis 74: Uses of higher capacity buses in transit service. Transportation Research Board of the National Academies, Washington, DC.

Henry, L., and T. Litman. 2006. Evaluating new transit program performance: Comparing rail and bus. Transport Policy 14, Victoria Transport Policy Institute, Victoria, BC, Canada.

Hensher, D. A., and T. F. Golob. 2008. Bus rapid transit systems: A comparative assessment. Transportation 35(4): 501-518.

Hensher, D. A., and W. G. Waters II. 1994. Light rail and bus priority systems: Choice or blind commitment? Research in Transportation Economics 3: 139-162.

Hess, D. B., B. D. Taylor, and A. C. Yoh. 2005. Light rail lite or cost-effective improvements to bus service: Evaluating costs of implementing bus rapid transit. Transportation Research Record 1927: 22-30.

Hsu, L. R. 2005. Capacity-based cost modeling for light rail and bus rapid transit systems. Dissertation, Florida International University, Miami.

Keeler, Theodore E., and Kenneth Small. 1975. The Full Costs of Urban Tranport, Part III: Automobile Costs and Final Intermodal Cost Comparisons. Institute of Urban \& Regional Development.

Kittleson and Associates. 2007. TCRP Report 118: Bus Rapid Transit Practitioner's Guide. Transportation Research Board of the National Academies, Washington, DC.

Kühn, F. 2002. Bus rapid or light rail transit for intermediate cities. Institut National de Recherche sur les Transports et leur Sécurité, Arcueil, France.

Levinson, H., S. Zimmerman, J. Clinger, S. Rutherford, R. Smith, J. Cracknell, and R. Soberman 2003. TCRP Report 90: Bus Rapid Transit: Vol. 1, Case Studies in Bus Rapid Transit, and Vol. 2, Implementation Guidelines. Transportation Research Board of the National Academies, Washington, DC.

Manitoba Hydro. Electricity. 2012. Utility Rate Comparisons. Retrieved from < h t tp:// www.hydro.mb.ca/regulatory_affairs/energy_rates/electricity/utility_rate_comp. shtml>. Accessed October 15, 2012.

Majeau-Bettez, Guillaume, Troy R. Hawkins, and Anders Hammer Strømman. 2011. Life cycle environmental assessment of lithium-ion and nickel metal hydride batteries for plug-in hybrid and battery electric vehicles. Environmental Science \& Technology 45.10: 4548-4554. 
Metro. 2014. East San Fernando Valley Transit Corridor. Retrieved July 21, 2014, from http://www.metro.net/projects/east-sfv/.

Meyer J. R., J. F. Kain, and M. Wohl. 1966. The Urban Transportation Problem. Harvard University Press, Cambridge, MA.

Natural Resources Canada. 2012. Energy use data handbook: 1990-2009. Government of Canada.

Nelson, L. 2014. San Fenando Valley light-rail line is back on the table. Los Angeles Times, July 12. Retrieved from http://www.latimes.com/local/la-me-valley-rail-20140712story.html

Parajuli, P. M., and S. C. Wirasinghe. 2001. A line haul transit technology selection model. Transportation Planning and Technology 24: 271-308.

Pilgrim, R. D. 2000. Are we pricing LRT systems out of range? A comparison of cost experiences. 8th Joint Conference on Light Rail, Dallas, Texas, November.

Puchalsky, C. M. 2005. Comparison of emissions from light rail transit and bus rapid transit. Transportation Research Record 1927: 31-37.

Qin, J., J. Weissmann, M. Euritt, and M. Martello. 1996. Evaluating the full costs of urban passenger transportation. Transportation Research Record 1518: 57-64. Retrieved from http://trb.metapress.com/index/q34u250741080878.pdf.

Region of Waterloo. 2010. About Waterloo Region. Retrieved from http://www.regionofwaterloo.ca, accessed September 26, 2012.

Region of Waterloo. 2012. Rapid Transit. Retrieved from <http://rapidtransit.regionofwaterloo.ca>, Accessed September 26, 2012.

Reilly, J., and H. Levinson. 2012. Public Transport Capacity Analysis Procedures for Developing Cities. World Bank, Washington, DC.

SEWRPC. 1998. Comparison of rail transit modes. SouthEastern Wisconsin Regional Planning Commission Newsletter 38(2), SouthEastern Wisconsin Regional Planning Commission, Waukesha, WI.

Siemens. 2007. S70 Light Rail Vehicle. Siemens Transportation Systems, Inc., Sacramento, CA.

STV/Ralph Whitehead and Associates. 2011. LYNX Blue Line Extension: Operations and maintenance quantities and costs. City of Charlotte. Charlotte Area Transit System. Charlotte, NC, May 24.

Sullivan, W.G., E. M. Wicks, and J.T. Luxhoj. 2003. Engineering Economy. 12th Edition. Prentice Hall, NJ.

Taylor, B., M. Garrett, and H. Iseki. 2000. Measuring cost variability in provision of transit service. Transportation Research Record 1735(1): 101-112. Retrieved from http://trb. metapress.com/index/JXM587768T253210.pdf. 
Tirachini, A., D. A. Hensher, and S. R. Jara-Díaz. 2010. Restating modal investment priority with and improved model for public transport analysis. Transportation Research Part E 46: 1148-1168.

Transportation Action Ontario. 2012. A more efficient use of scarce rapid transit dollars for Toronto. Toronto, ON, February.

US EPA. 2009. Nitrogen Oxides Emissions. Retrieved from http://cfpub.epa.gov/eroe/ index.cfm, accessed September 10, 2012.

Vuchic, V. 1999. Transportation for Livable Cities, 1st Ed. New Brunswick, NJ: Center for Urban Policy Research.

Vuchic, V. R. 2005. Light Rail and BRT: Competitive or complementary? Public Transport International 5.

Vuchic, V. R. 2005. Urban Transit Operations Planning and Economics. Hoboken, NJ: John Wiley \& Sons.

Wang, R. 2011. Autos, transit and bicycles: Comparing the costs in large Chinese cities. Transport Policy 18(1): 139-146. doi:10.1016/j.tranpol.2010.07.003.

World Bank. 2010. Data: Pump price for diesel fuel. Washington, DC. Retrieved from <http://data.worldbank.org/indicator/EP.PMP.DESL.CD>, accessed October 15, 2012.

Zhang, M. 2009. Bus versus rail: Meta-analysis of cost characteristics, carrying capacities, and land use impacts. Transportation Research Record 2110: 87-95.

Zimmerman, S. L., and H. Levinson. 2004. Vehicle selection for BRT: Issues and options. Journal of Public Transportation 7(1): 83-103.

\section{About the Authors}

Jeffrey M. Casello (jcasello@uwaterloo.ca) is an Associate Professor in the School of Planning and Department of Civil and Environmental Engineering at the University of Waterloo.

Geoffrey MCD. LeWIS (g4lewis@uwaterloo.ca) is an Assistant Professor in the School of Planning and School of Environment, Enterprise and Development at the University of Waterloo.

KEVIN YeUNG (Kevin.yeung@uwaterloo.ca) is a master's candidate in the School of Planning and Department of Civil and Environmental Engineering at the University of Waterloo.

Deborah Santiago-RodrígUez (dsantiag@uwaterloo.ca) holds an MASc. in Civil and Environmental Engineering from the University of Waterloo. 